\title{
High Willingness to Participate in Partner Notification among Women Attending Reproductive Health and STI Clinics in Shenzhen, China: A Cross-Sectional Study
}

\author{
Rongxing Weng ${ }^{1}{ }^{\mathbb{D}}$, Weiye $\mathrm{Yu}^{1}{ }^{1}$, Fuchang Hong ${ }^{1}$, Chunlai Zhang ${ }^{1}$, Lizhang Wen ${ }^{1}$, Feng Wang ${ }^{1}$, \\ Yiting Luo ${ }^{1}$, Jianbin Ye ${ }^{1}$, Fen Tang ${ }^{1}$, Honglin Wang ${ }^{1}$, Xiangsheng Chen ${ }^{2,3}$ and Yumao Cai ${ }^{1, *}$ \\ 1 Shenzhen Center for Chronic Disease Control, Shenzhen 518020, China; wrx0518@163.com (R.W.); \\ ywy2002@126.com (W.Y.); hfc0755@sina.com (F.H.); szzhchl@163.com (C.Z.); 13602609811@139.com (L.W.); \\ biowangfeng@163.com (F.W.); luoyitingcathy@126.com (Y.L.); yejianbin_gd@126.com (J.Y.); \\ tangfen_123@163.com (F.T.); wanghonglin0612@126.com (H.W.) \\ 2 Peking Union Medical College Institute of Dermatology, Chinese Academy of Medical Science and Peking \\ Union Medical College, Nanjing 210042, China; chenxs@ncstdlc.org \\ 3 National Center for Sexually Transmitted Disease Control, Nanjing 210042, China \\ * Correspondence: caiyumao@163.com; Tel./Fax: +86-755-2553-2840
}

Received: 4 December 2019; Accepted: 5 January 2020; Published: 7 January 2020

\begin{abstract}
Genital Chlamydia trachomatis (CT) is one of the most common sexually transmitted infections (STI) worldwide. We explored the factors associated with willingness to participate in partner notification (PN) among women attending reproductive health and STI clinics in Shenzhen, China. An anonymous questionnaire was used to collect the sociodemographic characteristics, STI histories, and willingness to participate in routine CT screening and partner notification. In total, $87.31 \%(n=10,780)$ of participants were willing to notify their sex partner(s) if they were diagnosed with a CT infection. Willingness to complete PN was significantly associated with: being married, residing in Shenzhen $\geq 1$ year, having completed junior college or higher, not currently reporting STI-related symptoms, willing to have routine CT screening, and having a correct understanding of the health sequelae of CT infection. Nearly all women surveyed at reproductive health and STI clinics in Shenzhen reported willingness to complete PN. Promoting PN in these settings could help detect a large number of additional CT cases. Our findings provide evidence and implications for public health interventions on PN and suggest that targeted interventions are urgently needed for particular subpopulations including those not currently married, with shorter residency, lower education, and less awareness about the dangers of CT infection.
\end{abstract}

Keywords: partner notification; Chlamydia trachomatis; willingness; factors

\section{Introduction}

Genital Chlamydia trachomatis (CT) is one of the most common sexually transmitted infections (STI) worldwide. The World Health Organization (WHO) indicated a substantial global burden of CT infections in 2016, with the pooled prevalence of $3.8 \%$ in women and about 124.3 million cases of CT worldwide in women and men aged 15-49 years of age [1]. Previous studies in China also showed a large burden of CT infections, with a prevalence of $4.1 \%$ among women [2] and a higher prevalence $(10.1 \%)$ among female patients attending sexual and reproductive health clinics [3]. Untreated CT infection in women is associated with several serious sequelae including pelvic inflammatory disease, ectopic pregnancy, chronic pelvic pain, and tubal factor infertility [4]. CT infections may also increase 
the risk of acquiring and transmitting human immunodeficiency virus (HIV), and around $80 \%$ of CT cases are asymptomatic [5,6].

In CT intervention programs and guidelines in several countries, including the United Kingdom [7], Canada [8], the Netherlands [9], and Germany [9], partner notification (PN) is an essential individual and public health strategy to avoid re-infection of a treated index patient and reduce the burden of infections $[10,11]$. To expand the active screening of CT, a program in China called Shenzhen Gonorrhea and Chlamydia intervention pilot (SGCIP) was launched by the Health and Family Planning Commission of Shenzhen Municipality in 2017. This pilot also included PN in the program process. Many individuals would not know about their infections if they were asymptomatic cases [12], and $\mathrm{PN}$ is an effective way to expand CT screening to sex partners. Failure to inform sex partners could represent a missed opportunity in the detection and treatment of numerous asymptomatic individuals. A previous study in the United States showed that effective PN could have a major impact on chlamydia prevalence, with millions of infections averted because of partner notification [13]. PN has also been proven to be cost-effective in terms of reducing the HIV burden [14]. The guidelines on HIV self-testing and partner notification from $\mathrm{WHO}$ indicated that $\mathrm{PN}$ is cost-effective in reaching high-risk individuals with rare harm or violence, and thus providing a strong recommendation for implementing PN [15]. These guidelines also summarized that high proportions of HIV-positive people could be diagnosed through assisted PN services [15]. There are four options for partner notification including provider referral, patient-based partner referral, expedited partner therapy, and contract referral [16], and one infected patient may use different strategies to notify different sex partners. The option of having health department professionals notify the partner(s) of their risk of being infected is considered as provider referral [17]. When index patients inform their partner(s) by themselves, this option is considered as patient-based partner referral [17]. Expedited partner therapy is a partner treatment approach in which the partner(s) of index patients get treatment prior to clinical evaluation [17]. In the contract referral, index patients prefer to inform their partner(s) within a certain time frame and agree that if they do not notify them within this time frame, disease intervention specialists will inform the partner(s) [17].

The rate of PN varies in different studies: 53\% successful direct patient referral in sub-Saharan Africa [11], 73\% successful PN in Sweden [18], 76.4\% successful PN in the United States [19], and 51\% successful PN by patient referral card in Peru [20]. Also, improving the efficacy of PN was found to be more cost-effective than increasing the coverage of CT screening [10]. From a systematic review, factors of partner notification were reported, such as female, higher education level, and regular partner as facilitators, and being married, stigma, fear of adverse reaction, and risk of intimate partner violence as barriers [11].

However, little is known about the acceptability of PN in the Chinese context and many patients in China may be very sensitive to PN because of social stigma and the fear of relationship breakdown [21]. Understanding what characteristics are associated with the willingness to participate in PN could inform future public health intervention efforts to implement and promote this prevention strategy. This study aimed to explore women's willingness to participate in PN and identify associated factors among women attending reproductive health and STI clinics in Shenzhen.

\section{Materials and Methods}

\subsection{Study Setting and Population}

Study sites were selected using a stratified purposeful sampling design. Six administrative districts in Shenzhen were included and within the selected districts, four hospitals with a high number of reported CT cases in each district were included for recruitment, except one district with only two hospitals. A total of 22 hospitals were included in the study. Patient eligibility criteria were as follows: (1) cis-gender women, (2) aged 18 to 49, inclusive, (3) having ever engaged in sexual activity, and (4) having not used any antibiotics in the last two weeks. A convenient sampling was used to recruit 
participants. From 1 April to 16 May 2018, the first 15 eligible patients per day in the obstetrics and gynecology, urology, and dermatology clinics were recruited for the questionnaire survey.

\subsection{Questionnaire Survey}

We provided intensive training in conducting questionnaire surveys for all study staff. The paper-based questionnaire surveys were administered one-on-one by the study staff. A set of anonymous structured questions was used to collect the information about sociodemographic characteristics and STI history (e.g., age, marital status, and chlamydia testing and diagnosis history), willingness to undergo routine CT screening, and willingness to participate in PN.

\subsection{Questions about CT-Related Knowledge and Willingness to Participate in Partner Notification (PN)}

Two questions assessed CT-related knowledge. Knowledge question 1, "What do you know about genital CT infections?" included four response options: (a) "Never heard of it," (b) "A kind of infectious disease," (c) "A kind of genital tract infection," and (d) "A kind of sexually transmitted disease." Response options were coded as follows: (a) "Lack of understanding," and (b), (c), or (d) as "Correct understanding," resulting in two knowledge levels. Knowledge question 2, "What do you know about the dangers of genital Chlamydia trachomatis infections for the human body?" included four response options: (a) "No danger," (b) "May affect sexual life," (c) "May affect fertility," and (d) "Know nothing about it." Response options were coded as follows: (a) "Incorrect understanding," (b) or (c) "Correct understanding," and (d) "Lack of understanding," resulting in three levels of knowledge. The question "If you were diagnosed with $\mathrm{CT}$, would you be willing to inform your partner?" was intended to obtain information on willingness to participate in PN from participants, with two possible responses ("No" and "Yes").

\subsection{Statistical Analyses}

All questionnaire data were double entered using Epi Data software (Epi Data for Windows; The Epi Data Association, Odense, Denmark). The frequency (\%) and mean \pm SD (standard deviation) were calculated for categorical variables and continuous variables, respectively. Univariate logistic regression analysis was used to obtain crude odds ratios (OR) and their $95 \%$ confidence intervals (CIs). Using a forward stepwise procedure, multivariate logistic regression analysis, including those variables with $p<0.10$ in the univariate logistic regression analysis, was used to obtain adjusted odds ratios (AOR) and their $95 \%$ CIs. We adopted a multivariable logistic regression model, defining the willingness to participate in partner notification as a dependent variable and age groups, marital status, separation, residency, residence time, education level, monthly income, insurance, sexual orientation, STI-related symptoms, willingness to undergo routine CT screening, having a new sexual partner or multiple sex partners in the past three months, and CT knowledge questions 1 and 2 as independent variables. All data analyses were performed with Statistical Package for Social Sciences (SPSS) version 21.0 software (SPSS Inc., Chicago, IL, USA). All tests were two-tailed, and $p<0.05$ was defined as statistically significant.

\subsection{Ethical Approval}

All participants provided written informed consent. This study was approved by the Ethical Review Committee of the Shenzhen Center for Chronic Disease Control (Approval No. 20180206).

\section{Results}

3.1. Sociodemographic Characteristics and Sexually Transmitted Infections (STI) Histories and the Correlates with Willingness to Participate in Partner Notification

The sociodemographic characteristics and STI histories of participants are shown in Table 1. We excluded 483 participants because of incomplete questionnaires, leaving 10,780 participants in the final analysis. The mean age was $31.58 \pm 7.09$. The majority of participants $(85.38 \%)$ were over 24 years old and $78.98 \%$ were married. One-tenth $(10.38 \%)$ of the participants lived alone or apart from 
their husbands or boyfriends, and 29.59\% were Shenzhen residents. The education level of two-fifths $(40.73 \%)$ of the participants was junior college or higher, and $64.38 \%$ had health insurance.

Table 1. Sociodemographic characteristics and STI histories of participants and the correlates with willingness to participate in partner notification.

\begin{tabular}{|c|c|c|c|c|c|}
\hline Variables & $\begin{array}{l}\text { Total } \\
N(\%)^{\text {a }}\end{array}$ & $\begin{array}{c}\text { Willing to } \\
\text { Participate in } \\
\text { Partner Notification }\end{array}$ & $\begin{array}{c}\text { Unwilling to } \\
\text { Participate in } \\
\text { Partner Notification }\end{array}$ & $x^{2}$ Value & $p$ Value \\
\hline Age groups $(n=10,716)$ & & & & 32.078 & $0.000 * *$ \\
\hline$\leq 24$ & $1567(14.62 \%)$ & $1299(82.90 \%)$ & $268(17.10 \%)$ & & \\
\hline$>24$ & $9149(85.38 \%)$ & $8056(88.05 \%)$ & $1093(11.95 \%)$ & & \\
\hline Marital status $(n=10,716)$ & & & & 47.042 & $0.000 * *$ \\
\hline Single/Divorced/Widowed & $2253(21.02 \%)$ & $1871(83.04 \%)$ & $382(16.96 \%)$ & & \\
\hline Married & $8463(78.98 \%)$ & $7486(88.46 \%)$ & $977(11.54 \%)$ & & \\
\hline Living alone or apart $(n=9066)$ & & & & 2.940 & 0.09 \\
\hline Yes & $941(10.38 \%)$ & $812(86.29 \%)$ & $129(13.71 \%)$ & & \\
\hline No & $8125(89.62 \%)$ & $7167(88.21 \%)$ & $958(11.79 \%)$ & & \\
\hline Shenzhen resident $(n=10,570)$ & & & & 58.501 & $0.000 * *$ \\
\hline No & $7442(70.41 \%)$ & $6391(85.88 \%)$ & $1051(14.12 \%)$ & & \\
\hline Yes & $3128(29.59 \%)$ & $2855(91.27 \%)$ & $273(8.73 \%)$ & & \\
\hline Length of residency $(n=10,616)$ & & & & 150.454 & $0.000 * *$ \\
\hline$<1$ year & $1366(12.87 \%)$ & $1052(77.01 \%)$ & $314(22.99 \%)$ & & \\
\hline$\geq 1$ year & $9250(87.13 \%)$ & $8218(88.84 \%)$ & $1032(11.16 \%)$ & & \\
\hline Education level $(n=10,674)$ & & & & 84.705 & $0.000 * *$ \\
\hline High school or lower & $6327(59.27 \%)$ & $5376(84.97 \%)$ & $951(15.03 \%)$ & & \\
\hline Junior college or higher & $4347(40.73 \%)$ & $3955(90.98 \%)$ & $392(9.02 \%)$ & & \\
\hline Monthly income (RMB) $(n=9838)$ & & & & 39.969 & $0.000 * *$ \\
\hline $0-4999$ & $4213(42.82 \%)$ & $3608(85.64 \%)$ & $605(14.36 \%)$ & & \\
\hline 5000-9999 & $4101(41.69 \%)$ & $3581(87.32 \%)$ & $520(12.68 \%)$ & & \\
\hline $10,000+$ & $1524(15.49 \%)$ & $1401(91.93 \%)$ & $123(8.07 \%)$ & & \\
\hline Health insurance $(n=10,655)$ & & & & 25.731 & $0.000 * *$ \\
\hline No & $3795(35.62 \%)$ & $3230(85.11 \%)$ & $565(14.89 \%)$ & & \\
\hline Yes & $6860(64.38 \%)$ & $6073(88.53 \%)$ & $787(11.47 \%)$ & & \\
\hline Sexual orientation $(n=10,573)$ & & & & 3.830 & 0.05 \\
\hline Homosexuality/bisexuality & $150(1.42 \%)$ & $139(92.67 \%)$ & $11(7.33 \%)$ & & \\
\hline Heterosexuality & $10423(98.58 \%)$ & $9102(87.33 \%)$ & $1321(12.67 \%)$ & & \\
\hline Ever CT tested $(n=10,517)$ & & & & 1.692 & 0.19 \\
\hline No & $9608(91.36 \%)$ & $8386(87.28 \%)$ & $1222(12.72 \%)$ & & \\
\hline Yes & $909(8.64 \%)$ & $807(88.78 \%)$ & $102(11.22 \%)$ & & \\
\hline \multicolumn{6}{|l|}{ Ever CT diagnosed $(n=10,669)$} \\
\hline No & $8897(83.39 \%)$ & $7764(87.27 \%)$ & $1133(12.73 \%)$ & 1.475 & 0.48 \\
\hline Yes & $642(6.02 \%)$ & $569(88.63 \%)$ & $73(11.37 \%)$ & & \\
\hline Forgot & $1130(10.59 \%)$ & $979(86.64 \%)$ & $151(13.36 \%)$ & & \\
\hline Current STI-related symptoms $(n=10,663)$ & & & & 130.905 & $0.000 * *$ \\
\hline Yes & $6593(61.83 \%)$ & $5562(84.36 \%)$ & $1031(15.64 \%)$ & & \\
\hline No & $4070(38.17 \%)$ & $3743(91.97 \%)$ & $327(8.03 \%)$ & & \\
\hline $\begin{array}{l}\text { Having a new sexual partner or multiple } \\
\text { sex partners, past } 3 \text { months }(n=10,628)\end{array}$ & & & & 3.879 & $0.04 *$ \\
\hline Yes & $3138(29.53 \%)$ & $2711(86.39 \%)$ & $427(13.61 \%)$ & & \\
\hline No & $7490(70.47 \%)$ & $6575(87.78 \%)$ & $915(12.22 \%)$ & & \\
\hline CT screening willingness $(n=10,366)$ & & & & 1774.269 & $0.000 * *$ \\
\hline Unwilling & $1026(9.90 \%)$ & $467(45.52 \%)$ & $559(54.48 \%)$ & & \\
\hline Willing & $9340(90.10 \%)$ & $8573(91.79 \%)$ & $767(8.21 \%)$ & & \\
\hline Knowledge Q1 $(n=10,669)$ & & & & 0.952 & 0.33 \\
\hline Lack of understanding & $8034(75.30 \%)$ & $7006(87.20 \%)$ & $1028(12.80 \%)$ & & \\
\hline Correct understanding & $2635(24.70 \%)$ & $2317(87.93 \%)$ & $318(12.07 \%)$ & & \\
\hline Knowledge Q2 $(n=10,747)$ & & & & 373.406 & $0.000 * *$ \\
\hline Incorrect understanding & $296(2.75 \%)$ & $151(51.01 \%)$ & $145(48.99 \%)$ & & \\
\hline Lack of understanding & $7802(72.60 \%)$ & $6845(87.73 \%)$ & $957(12.27 \%)$ & & \\
\hline Correct understanding & $2649(24.65 \%)$ & $2389(90.18 \%)$ & $260(9.82 \%)$ & & \\
\hline $\begin{array}{l}\text { Willingness to participate in partner } \\
\text { notification }(n=10,780)\end{array}$ & & & & - & - \\
\hline Unwilling & $1368(12.69 \%)$ & - & - & & \\
\hline Willing & $9412(87.31 \%)$ & - & - & & \\
\hline
\end{tabular}

a \%: Constituent ratio. ${ }^{*} p<0.05,{ }^{* *} p<0.001$. Abbreviations: CT, chlamydia trachomatis; STI, sexually transmitted infections. 
Almost all (91.36\%) participants had not been tested for CT infections before, and 83.39\% had not been diagnosed with a CT infection before. More than half $(61.83 \%)$ of the participants had STI-related symptoms on the day they completed the questionnaire, and $29.53 \%$ of participants had a new sexual partner or multiple sex partners in the last three months.

The correlates with willingness to participate in PN are shown in Table 1. Participants aged $>24$ were more willing to participate in PN than those aged $\leq 24$. Participants currently married were more willing to participate in PN than those with other marital status. Participants with Shenzhen residency were more willing to participate in $\mathrm{PN}$ than those with residency in other cities or provinces. Participants with $\geq 1$ year of residency were more willing to participate in $\mathrm{PN}$ than those with $<1$ year of residency. Higher willingness to participate in PN was also found in participants with a higher education level, higher monthly income, and health insurance; those without a new sexual partner or multiple sex partners; those willing to have routine CT screening; and those with a correct understanding of the sequalae of CT infection.

\subsection{CT-Related Knowledge and Willingness to Undergo Routine CT Screening and Partner Notification}

CT-related knowledge and willingness to undergo routine CT screening and partner notification are presented in Table 1 . Almost all participants $(90.10 \%)$ were willing to have routine CT screening and $87.31 \%$ would be willing to notify their sex partners if they were diagnosed with a CT infection. Around three-quarters of respondents lacked understanding of chlamydia infections (knowledge Q1 = $75.30 \%$; Q2 = 72.60\%).

\subsection{Factors Associated with Willingness to Participate in Partner Notification}

The results of both univariate and multivariate logistic regression analysis are shown in Table 2. A total of 13 variables associated with the willingness to participate in partner notification at $p<0.10$ in the univariate analysis were included in the multivariate logistic regression analysis. The results from the multivariable logistic regression model indicated that the willingness to participate in partner notification was positively associated with being married (OR $=1.53,95 \% \mathrm{CI}=1.17-2.01)$, residing in Shenzhen for one year or more $(\mathrm{OR}=2.26,95 \% \mathrm{CI}=1.84-2.77)$, junior college education or higher $(\mathrm{OR}=1.61,95 \% \mathrm{CI}=1.31-1.99)$, not currently experiencing STI-related symptoms $(\mathrm{OR}=2.01,95 \%$ $\mathrm{CI}=1.67-2.42)$, and being willing to have routine $\mathrm{CT}$ screening $(\mathrm{OR}=11.75,95 \% \mathrm{CI}=9.76-14.14)$; and negatively associated with having incorrect understanding of the sequalae of CT infection $(\mathrm{OR}=$ $0.26,95 \% \mathrm{CI}=0.18-0.39)$.

Table 2. Logistic regression analysis of factors associated with willingness to participate in partner notification.

\begin{tabular}{lcccc}
\hline \multicolumn{1}{c}{ Variables } & Crude OR (95\% CI) & $p$ Values & Adjusted OR (95\% CI) & $p$ Values \\
\hline Age groups & & & \\
\hline$\leq 24$ & Reference & & Reference & \\
$>24$ & $1.52(1.31,1.76)$ & $0.000^{* *}$ & $1.12(0.85,1.48)$ & 0.420 \\
\hline Marital status & & & \\
\hline Single/Divorced/Widowed & Reference & & Reference & \\
Married & $1.56(1.38,1.78)$ & $0.000^{* *}$ & $1.53(1.17,2.01)$ & $0.002 *$ \\
\hline Living alone or apart & & & \\
\hline Yes & Reference & & \\
No & $1.19(0.98,1.45)$ & $0.087^{*}$ & $1.01(0.79,1.31)$ & 0.913 \\
\hline Shenzhen resident & & & \\
\hline No & Reference & & \\
Yes & $1.72(1.49,1.98)$ & $0.000^{* *}$ & $0.97(0.79,1.21)$ & 0.809 \\
\hline
\end{tabular}


Table 2. Cont.

\begin{tabular}{|c|c|c|c|c|}
\hline Variables & Crude OR $(95 \%$ CI) & $p$ Values & Adjusted OR (95\% CI) & $p$ Values \\
\hline \multicolumn{5}{|l|}{ Length of residency } \\
\hline$<1$ year & Reference & & Reference & \\
\hline$\geq 1$ year & $2.38(2.06,2.74)$ & $0.000 * *$ & $2.26(1.84,2.77)$ & $0.000 * *$ \\
\hline \multicolumn{5}{|l|}{ Education level } \\
\hline High school or lower & Reference & & Reference & \\
\hline Junior college or higher & $1.78(1.58,2.02)$ & $0.000^{* *}$ & $1.61(1.31,1.99)$ & $0.000 * *$ \\
\hline \multicolumn{5}{|l|}{ Monthly income (RMB) } \\
\hline $0-4999$ & Reference & & Reference & \\
\hline 5000-9999 & $1.15(1.02,1.31)$ & $0.025 *$ & $1.00(0.83,1.20)$ & 0.963 \\
\hline $10,000+$ & $1.91(1.56,2.34)$ & $0.000 * *$ & $1.20(0.89,1.62)$ & 0.226 \\
\hline \multicolumn{5}{|l|}{ Health insurance } \\
\hline No & Reference & & Reference & \\
\hline Yes & $1.35(1.20,1.52)$ & $0.000 * *$ & $1.02(0.85,1.22)$ & 0.829 \\
\hline \multicolumn{5}{|l|}{ Sexual orientation } \\
\hline Homosexuality/bisexuality & Reference & & Reference & \\
\hline Heterosexuality & $0.55(0.29,1.01)$ & 0.054 & $0.74(0.34,1.63)$ & 0.462 \\
\hline \multicolumn{5}{|l|}{ Ever CT tested } \\
\hline No & Reference & & & \\
\hline Yes & $1.15(0.93,1.43)$ & 0.194 & & \\
\hline \multicolumn{5}{|l|}{ Ever CT diagnosed } \\
\hline No & Reference & & & \\
\hline Yes & $1.14(0.88,1.46)$ & 0.316 & & \\
\hline Forgot & $0.95(0.79,1.14)$ & 0.552 & & \\
\hline \multicolumn{5}{|c|}{ Current STI-related symptoms } \\
\hline Yes & Reference & & Reference & \\
\hline No & $2.12(1.86,2.42)$ & $0.000 * *$ & $2.01(1.67,2.42)$ & $0.000 * *$ \\
\hline \multicolumn{5}{|c|}{$\begin{array}{l}\text { Having a new sexual partner or } \\
\text { multiple sex partners, past } 3 \text { months }\end{array}$} \\
\hline Yes & Reference & & Reference & \\
\hline No & $1.13(1.00,1.28)$ & $0.049 *$ & $1.09(0.91,1.31)$ & 0.356 \\
\hline \multicolumn{5}{|l|}{ CT Screening willingness } \\
\hline Unwilling & Reference & & Reference & \\
\hline Willing & $13.38(11.59,15.44)$ & $0.000^{* *}$ & $11.75(9.76,14.14)$ & $0.000 * *$ \\
\hline \multicolumn{5}{|l|}{ Knowledge Q1 } \\
\hline Correct understanding & Reference & & & \\
\hline Lack of understanding & $0.94(0.82,1.07)$ & 0.329 & & \\
\hline \multicolumn{5}{|l|}{ Knowledge Q2 } \\
\hline Correct understanding & Reference & & Reference & \\
\hline Lack of understanding & $0.78(0.67,0.90)$ & $0.001 *$ & $0.91(0.74,1.11)$ & 0.342 \\
\hline Incorrect understanding & $0.11(0.09,0.15)$ & $0.000 * *$ & $0.26(0.18,0.39)$ & $0.000 * *$ \\
\hline
\end{tabular}

${ }^{*} p<0.05,{ }^{* *} p<0.001$. Abbreviations: OR, odds ratio; CI, confidence interval; $\mathrm{CT}$, chlamydia trachomatis; STI, sexually transmitted infections.

\section{Discussion}

Our study indicated that the willingness to participate in partner notification in CT infections was very high $(87 \%)$ among women attending reproductive health and STI clinics in Shenzhen, China. Several studies in different countries have reported similar results. A study in Botswana suggested that most pregnant women (98\%) were willing to notify their partner about their STI results [22]. Buchsbaum et al. found that $98 \%$ of female adolescents expressed willingness to inform their partner of a STI diagnosis in the southern United States [19]. Results from a systematic review showed 
that many index patients, ranging from 58 to $93 \%$, were willing to give their STI results to their partner [23]. Our findings provide data in support of regular CT screening projects and suggest that the implementation and promotion of PN in clinics may be helpful for expanding CT screening among high-risk groups. Among the different types of $\mathrm{PN}$, although provider referral has been found to be the most effective strategy to decrease re-infection rates and increase the number of partners treated [24], it may be impractical to manage sex partner notification through provider referral because of the large number of CT cases and limited public health resources. This leaves patient-based referral (the focus of the current study) as the most common and feasible referral strategy for CT infection $[25,26]$. Even with a relatively lower efficiency than provider referral, patient referral could still help detect a significant number of additional CT cases at low costs.

In our study, married participants were more willing to notify their partner than those with other marital status, which was consistent with the results of two other studies [27,28]. It is suggested that interdependency may be a motivation for married individuals to have a higher concern for their spouse's health [27], which leads to higher willingness to participate in PN. Our study also found that participants who had lived in Shenzhen longer and who had higher education were more willing to notify their partner about CT infections. Taken together, these findings may be partly explained by Shenzhen's large floating population-a common phenomenon in China's modern cities. Migrants in this population tend to be unmarried, have low education, and stay in the city for a short time [29]. The implications of this for successful PN suggest the importance of education-level-appropriate programs on sexual and reproductive health that highlight the health benefits of informing partners.

Our study may be the first survey to report the following findings. Lower willingness was found among participants with STI-related symptoms than those without symptoms. Patients would think that they are closer to the STIs when they have STI-related symptoms, which was proven by a previous study in which around $50 \%$ of men said that they would be concerned about chlamydia only if they had symptoms [30]. Because of the self-perceived high risk of STI acquisition, patients with STI-related symptoms may be more concerned about the outcomes of PN such as relationship breakdown and partner violence, and be more cautious about expressing their willingness to engage in PN. However, it was found that there was no association between symptoms and CT infection in many studies [19,31-34], which means that asymptomatic patients can also be considered to have the same risk of CT infection as symptomatic patients. Because of the low level of awareness about CT infection (Knowledge Q1) in our study, asymptomatic individuals may underestimate their risk of CT infection, and may become cautious about participating in PN after they get diagnosed. A study showed that the rate of successful PN was lower than the rate of willingness [23]. Based on the above findings, targeted interventions should be implemented in symptomatic patients to motivate them to participate in PN, and CT-related information should also be distributed to all patients. Participants who were open to routine CT screening had an 11-fold higher willingness to undergo partner notification. This finding might be explained by a higher concern for one's health. Those who are willing to have routine CT screening are more likely to be concerned about their health, and thus also willing to notify their partner(s) of a diagnosis. Also, CT screening and PN could be implemented in the same intervention and it has been proven that a combination of CT screening and PN could have the greatest impact on CT prevention [13]. Therefore, a comprehensive intervention focused on the motivations of both PN willingness and CT screening willingness could be further considered in future projects.

An important finding of this study was that participants who incorrectly thought there were no health dangers to $\mathrm{CT}$ infection were less willing to inform their partner about CT test results, suggesting that lower health literacy may be an important barrier to PN. Poor knowledge of the sequalae of CT infection could hinder the effectiveness of CT-related interventions such as screening [30], which could also explain the unwillingness to engage in PN in our study. Also, poor knowledge could contribute to an increase in risky behavior and thus increase the risk of STDs/HIV acquisition [35], and poor knowledge could also lead to delays in appropriate treatment [36]. Poor knowledge of STDs was seen in many studies [36-39] and is considered a major issue in disease prevention, so CT-related education, 
including information about complications, modes of transmission, and asymptomatic presentation, should be implemented in clinics to increase patient awareness and potentially facilitate PN.

This study has several limitations. First, the convenience sampling method may undermine the representativeness of the sample. This methodological limitation is balanced by the large sample size across six city districts and 22 hospitals. Second, the response rate could not be obtained in our study because related data were not collected. Third, these findings may not be generalizable to other Chinese cities. However, as Shenzhen City is comprised of a majority migrant population, the views represented in our data included those of individuals from many parts of China. Fourth, the social desirability bias related to sexual behavior and health behaviors may have influenced participants' survey responses. Lastly, our study measured the willingness, not behavioral intentions or actual behavior. Future studies are needed to understand how to translate the high willingness of PN into actual notification or partner treatment. The associations we found (e.g., education level, symptom status) may provide a starting point for developing promising intervention strategies in this area.

\section{Conclusions}

To our knowledge, this is the first large-scale population-based study in China to report the willingness to participate in PN and its associated factors. This study reported a high willingness to participate in PN of CT infections among women attending reproductive health and STI clinics in Shenzhen, and provided evidence for health authorities in China to develop and implement guidelines or interventions for PN in CT infections. Our findings provide evidence and implications for public health interventions on PN and suggest that targeted interventions are urgently needed for particular subpopulations, including those not currently married and those with a shorter residency time, lower education, and less awareness about the dangers of $\mathrm{CT}$ infection.

Author Contributions: Conceptualization, R.W. and Y.C.; methodology, R.W.; software, R.W.; validation, W.Y., F.H., L.W., and C.Z.; investigation, F.W., Y.L., J.Y., F.T., and H.W.; data curation, W.Y., F.H., L.W., C.Z., F.W., Y.L., J.Y., F.T., and H.W.; writing-original draft preparation, R.W.; writing—review and editing, Y.C. and X.C.; supervision, Y.C. and X.C.; project administration, Y.C. and X.C. All authors have read and agreed to the published version of the manuscript.

Funding: This study was supported by Sanming project of Medicine in Shenzhen (No. SZSM201611077).

Acknowledgments: We are indebted to all participants in this study for their cooperation. We thank the staff at all participated hospitals, Center for chronic diseases control and Center for chronic diseases control.

Conflicts of Interest: The authors declare no conflict of interest.

\section{References}

1. Rowley, J.; Vander Hoorn, S.; Korenromp, E.; Low, N.; Unemo, M.; Abu-Raddad, L.; Chico, R. Global and Regional Estimates of the Prevalence and Incidence of Four Curable Sexually Transmitted Infections in 2016. WHO Bull. 2019, 97, 548-562. [CrossRef]

2. Luo, Z.Z.; Li, W.; Wu, Q.H.; Zhang, L.; Tian, L.S.; Liu, L.L.; Ding, Y.; Yuan, J.; Chen, Z.W.; Lan, L.N.; et al. Population-based study of chlamydial and gonococcal infections among women in Shenzhen, China: Implications for programme planning. PLoS ONE 2018, 13, e0196516. [CrossRef]

3. Yan, R.L.; Ye, Y.F.; Fan, Q.Y.; Huang, Y.H.; Wen, G.C.; Li, L.M.; Cai, Y.M.; Feng, T.J.; Huang, Z.M. Chlamydia trachomatis infection among patients attending sexual and reproductive health clinics: A cross-sectional study in Bao'an District, Shenzhen, China. PLoS ONE 2019, 14, e0212292. [CrossRef]

4. Haggerty, C.L.; Gottlieb, S.L.; Taylor, B.D.; Low, N.; Xu, F.; Ness, R.B. Risk of sequelae after Chlamydia trachomatis genital infection in women. J. Infect. Dis. 2010, 201 (Suppl. 2), S134-S155. [CrossRef]

5. Holmes, K.K.; Sparling, P.F.; Stamm, W.E.; Piot, P.; Wasserheit, J.N.; Corey, L. Sexually Transmitted Diseases; McGraw-Hill Medical: New York, NY, USA, 2008.

6. Peipert, J.F. Clinical practice. Genital chlamydial infections. N. Engl. J. Med. 2003, 349, 2424-2430. [CrossRef] [PubMed] 
7. Public Health England. Opportunistic Chlamydia Screening of Young Adults in England. Available online: https://assets.publishing.service.gov.uk/government/uploads/system/uploads/attachment_data/file/ 497371/Opportunistic_Chlamydia_Screening_Evidence_Summary_April_2014.pdf (accessed on 22 July 2019).

8. Public Health Agency of Canada. Canadian Guidelines on Sexually Transmitted Infections-Management and Treatment of Specific Infections-Chlamydial Infections. Available online: https:/www.canada.ca/ en/public-health/services/infectious-diseases/sexual-health-sexually-transmitted-infections/canadianguidelines/sexually-transmitted-infections/canadian-guidelines-sexually-transmitted-infections-30.html (accessed on 22 July 2019).

9. van den Broek, I.V.; Sfetcu, O.; van der Sande, M.A.; Andersen, B.; Herrmann, B.; Ward, H.; Gotz, H.M.; Uuskula, A.; Woodhall, S.C.; Redmond, S.M.; et al. Changes in chlamydia control activities in Europe between 2007 and 2012: A cross-national survey. Eur. J. Public Health 2016, 26, 382-388. [CrossRef] [PubMed]

10. Althaus, C.L.; Turner, K.M.; Mercer, C.H.; Auguste, P.; Roberts, T.E.; Bell, G.; Herzog, S.A.; Cassell, J.A.; Edmunds, W.J.; White, P.J.; et al. Effectiveness and cost-effectiveness of traditional and new partner notification technologies for curable sexually transmitted infections: Observational study, systematic reviews and mathematical modelling. Health Technol. Assess. 2014, 18,1-100. [CrossRef] [PubMed]

11. Taleghani, S.; Joseph-Davey, D.; West, S.B.; Klausner, H.J.; Wynn, A.; Klausner, J.D. Acceptability and efficacy of partner notification for curable sexually transmitted infections in sub-Saharan Africa: A systematic review. Int. J. STD AIDS 2019, 30, 292-303. [CrossRef] [PubMed]

12. Hogben, M.; Kissinger, P. A review of partner notification for sex partners of men infected with Chlamydia. Sex Transm Dis. 2008, 35, S34-S39. [CrossRef]

13. Ronn, M.M.; Tuite, A.R.; Menzies, N.A.; Wolf, E.E.; Gift, T.L.; Chesson, H.W.; Torrone, E.; Berruti, A.; Mazzola, E.; Galer, K.; et al. The Impact of Screening and Partner Notification on Chlamydia Prevalence and Numbers of Infections Averted in the United States, 2000-2015: Evaluation of Epidemiologic Trends Using a Pair-Formation Transmission Model. Am. J. Epidemiol. 2019, 188, 545-554. [CrossRef]

14. Sharma, M.; Smith, J.A.; Farquhar, C.; Ying, R.; Cherutich, P.; Golden, M.; Wamuti, B.; Bukusi, D.; Spiegel, H.; Barnabas, R.V. Assisted partner notification services are cost-effective for decreasing HIV burden in western Kenya. AIDS 2018, 32, 233-241. [CrossRef] [PubMed]

15. WHO Guidelines Approved by the Guidelines Review Committee. In Guidelines on HIV Self-Testing and Partner Notification: Supplement to Consolidated Guidelines on HIV Testing Services; World Health Organization: Geneva, Switzerland, 2016.

16. Rahman, M.M.; Khan, M.; Gruber, D. A Low-Cost Partner Notification Strategy for the Control of Sexually Transmitted Diseases: A Case Study From Louisiana. Am. J. Public Health 2015, 105, 1675-1680. [CrossRef] [PubMed]

17. Centers for Disease Control and Prevention. Recommendations for partner services programs for HIV infection, syphilis, gonorrhea, and chlamydial infection. MMWR Recomm. Rep. 2008, 57, 1-83.

18. Sylvan, S.P.; Hedlund, J. Efficacy of partner notification for Chlamydia trachomatis among young adults in youth health centres in Uppsala County, Sweden. J. Eur. Acad. Derm. Venereol. 2009, 23, 517-522. [CrossRef]

19. Buchsbaum, A.; Gallo, M.F.; Whiteman, M.K.; Cwiak, C.; Goedken, P.; Kraft, J.M.; Jamieson, D.J.; Kottke, M. Sexually transmitted disease partner notification among African-American, adolescent women. Infect. Dis. Obs. Gynecol. 2014, 2014, 619632. [CrossRef]

20. Clark, J.L.; Segura, E.R.; Oldenburg, C.E.; Salvatierra, H.J.; Rios, J.; Perez-Brumer, A.G.; Gonzales, P.; Sheoran, B.; Sanchez, J.; Lama, J.R. Traditional and Web-Based Technologies to Improve Partner Notification Following Syphilis Diagnosis Among Men Who Have Sex With Men in Lima, Peru: Pilot Randomized Controlled Trial. J. Med. Internet Res. 2018, 20, e232. [CrossRef]

21. Wang, A.L.; Peng, R.R.; Tucker, J.D.; Cohen, M.S.; Chen, X.S. Partner notification uptake for sexually transmitted infections in China: A systematic literature review. Sex. Transm. Infect. 2012, 88, 386-393. [CrossRef]

22. Offorjebe, O.A.; Wynn, A.; Moshashane, N.; Joseph Davey, D.; Arena, K.; Ramogola-Masire, D.; Gaolebale, P.; Morroni, C.; Klausner, J.D. Partner notification and treatment for sexually transmitted infections among pregnant women in Gaborone, Botswana. Int. J. STD AIDS 2017, 28, 1184-1189. [CrossRef]

23. Alam, N.; Chamot, E.; Vermund, S.H.; Streatfield, K.; Kristensen, S. Partner notification for sexually transmitted infections in developing countries: A systematic review. BMC Public Health 2010, 10, 19. [CrossRef]

24. Ferreira, A.; Young, T.; Mathews, C.; Zunza, M.; Low, N. Strategies for partner notification for sexually transmitted infections, including HIV. Cochrane Database Syst. Rev. 2013. [CrossRef] 
25. Golden, M.R.; Hogben, M.; Handsfield, H.H.; St. Lawrence, J.S.; Potterat, J.J.; Holmes, K.K. Partner notification for HIV and STD in the United States: Low coverage for gonorrhea, chlamydial infection, and HIV. Sex. Transm. Dis. 2003, 30, 490-496. [CrossRef]

26. St. Lawrence, J.S.; Montano, D.E.; Kasprzyk, D.; Phillips, W.R.; Armstrong, K.; Leichliter, J.S. STD screening, testing, case reporting, and clinical and partner notification practices: A national survey of US physicians. Am. J. Public Health 2002, 92, 1784-1788. [CrossRef]

27. Alam, N.; Streatfield, P.K.; Khan, S.I.; Momtaz, D.; Kristensen, S.; Vermund, S.H. Factors associated with partner referral among patients with sexually transmitted infections in Bangladesh. Soc. Sci. Med. 2010, 71, 1921-1926. [CrossRef] [PubMed]

28. Clark, J.L.; Long, C.M.; Giron, J.M.; Cuadros, J.A.; Caceres, C.F.; Coates, T.J.; Klausner, J.D. Partner notification for sexually transmitted diseases in Peru: Knowledge, attitudes, and practices in a high-risk community. Sex. Transm. Dis. 2007, 34, 309-313. [CrossRef] [PubMed]

29. Mou, J.; Griffiths, S.M.; Fong, H.F.; Dawes, M.G. Defining migration and its health impact in China. Public Health 2015, 129, 1326-1334. [CrossRef] [PubMed]

30. Lorimer, K.; Hart, G.J. Knowledge of Chlamydia trachomatis among men and women approached to participate in community-based screening, Scotland, UK. BMC Public Health 2010, 10, 794. [CrossRef] [PubMed]

31. Tadesse, E.; Teshome, M.; Amsalu, A.; Shimelis, T. Genital Chlamydia trachomatis Infection among Women of Reproductive Age Attending the Gynecology Clinic of Hawassa University Referral Hospital, Southern Ethiopia. PLoS ONE 2016, 11, e0168580. [CrossRef] [PubMed]

32. Huffam, S.; Chow, E.P.F.; Leeyaphan, C.; Fairley, C.K.; Hocking, J.S.; Phillips, S.; Tabrizi, S.N.; Bellhouse, C.; Bradshaw, C.S.; Fehler, G.; et al. Chlamydia Infection Between Men and Women: A Cross-Sectional Study of Heterosexual Partnerships. Open Forum Infect. Dis. 2017, 4. [CrossRef]

33. Dela, H.; Attram, N.; Behene, E.; Kumordjie, S.; Addo, K.K.; Nyarko, E.O.; Kyei, N.N.A.; Carroll, J.N.A.; Kwakye, C.; Duplessis, C.A.; et al. Risk factors associated with gonorrhea and chlamydia transmission in selected health facilities in Ghana. BMC Infect. Dis. 2019, 19, 425. [CrossRef]

34. Yang, L.G.; Zhang, X.H.; Zhao, P.Z.; Chen, Z.Y.; Ke, W.J.; Ren, X.Q.; Wang, L.Y.; Chen, W.Y.; Tucker, J.D. Gonorrhea and chlamydia prevalence in different anatomical sites among men who have sex with men: A cross-sectional study in Guangzhou, China. BMC Infect. Dis. 2018, 18, 675. [CrossRef]

35. Zhang, X.; Jia, M.; Chen, M.; Luo, H.; Chen, H.; Luo, W.; Zhang, W.; Ma, Y.; Yang, C.; Yang, Y.; et al. Prevalence and the associated risk factors of HIV, STIs and HBV among men who have sex with men in Kunming, China. Int. J. STD AIDS 2017, 28, 1115-1123. [CrossRef] [PubMed]

36. Nguyen, S.H.; Dang, A.K.; Vu, G.T.; Nguyen, C.T.; Le, T.H.T.; Truong, N.T.; Hoang, C.L.; Tran, T.T.; Tran, T.H.; Pham, H.Q.; et al. Lack of Knowledge about Sexually Transmitted Diseases (STDs): Implications for STDs Prevention and Care among Dermatology Patients in an Urban City in Vietnam. Int. J. Environ. Res. Public Health 2019, 16. [CrossRef] [PubMed]

37. El-Tholoth, H.S.; Alqahtani, F.D.; Aljabri, A.A.; Alfaryan, K.H.; Alharbi, F.; Alhowaimil, A.A.; Alkharji, A.; Alrwaily, A.; Obied, A.; Al-Afraa, T. Knowledge and attitude about sexually transmitted diseases among youth in Saudi Arabia. Urol. Ann. 2018, 10, 198-202. [CrossRef] [PubMed]

38. Grad, A.I.; Senila, S.C.; Cosgarea, R.; Tataru, A.D.; Vesa, S.C.; Vica, M.L.; Matei, H.V.; Ungureanu, L. Sexual Behaviors, Attitudes, and Knowledge about Sexually Transmitted Infections: A Cross-sectional Study in Romania. Acta Derm. Croat. 2018, 26, 25-32.

39. Keizur, E.M.; Bristow, C.C.; Baik, Y.; Klausner, J.D. Knowledge and testing preferences for Chlamydia trachomatis, Neisseria gonorrhoeae, and Trichomonas vaginalis infections among female undergraduate students. J. Am. Coll. Health 2019, 1-8. [CrossRef] [PubMed]

(C) 2020 by the authors. Licensee MDPI, Basel, Switzerland. This article is an open access article distributed under the terms and conditions of the Creative Commons Attribution (CC BY) license (http://creativecommons.org/licenses/by/4.0/). 